Article

\title{
Photophysical Properties of Nitrated and Halogenated Phosphorus Tritolylcorrole Complexes: Insights from Theory
}

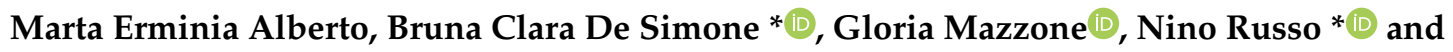 \\ Marirosa Toscano \\ Dipartimento di Chimica e Tecnologie Chimiche, Università della Calabria, Cubo 14C, Via P. Bucci, \\ 87036 Arcavacata di Rende, CS, Italy; malberto@unical.it (M.E.A.); gmazzone@unical.it (G.M.); \\ m.toscano@unical.it (M.T.) \\ * Correspondence: bruna.desimone@unical.it (B.C.D.S.); nrusso@unical.it (N.R.); \\ Tel.: +39-0984-492057 (B.C.D.S.); +39-0984-492106 (N.R.)
}

Academic Editors: M. Graça P. M. S. Neves, M. Amparo F. Faustino and Nuno M. M. Moura Received: 28 September 2018; Accepted: 25 October 2018; Published: 26 October 2018

\begin{abstract}
The photophysical properties of a series of nitrated and halogenated phosphorus tritolylcorrole complexes were studied in dichloromethane solvent by using the density functional theory. Particular emphasis was given to the absorption spectra, the energy gap between the excited singlet and triplet states, and the magnitude of the spin-orbit couplings for a series of possible intersystem crossing channels between those excited states. The proposed study provides a better description of the photophysical properties of these systems while giving insights into their possible use as photosensitizers in photodynamic therapy.
\end{abstract}

Keywords: phosphorus tritolylcorrole; photodynamic therapy; density functional theory; spin-orbit coupling; heavy atom effect

\section{Introduction}

Starting from the first reported synthesis of corroles by Johnson and Kay in 1964 [1], the interest in these porphyrin-like systems has grown considerably due to advances in their efficient synthesis combined with relatively easy options for varying the axial ligands, the central metal atom and the peripheral substituents. Their distinctive properties, often different from the analogues porphyrin systems, allow many applications in different fields of modern chemistry [2,3]. In particular, free ligand corroles and their metal coordinated derivatives have been proposed as applicable to optical imaging, dye-sensitized solar cells [4], electron and energy transfer systems [5], photodynamic detection [6], drug candidates against oxidative stress [7], catalysis [8] and photodynamic therapy [9]. Research has mainly focused on bare corroles and their complexes with different metal ions [2,3,10,11]. Also, corrole complexes with nonmetals have received considerable interest in recent years [12] and the synthetic strategies and characterization of the $\mathrm{P}(\mathrm{V})$ complexes have opened a new horizon in corroles chemistry [13-17]. Amongst these, halogenated derivatives have attracted particular interest due to the presence of halogen atoms, which provide very interesting photophysical properties to these systems [13-15,18]. Pomarico et al. [13] have recently synthesized a series of phosphorus (V) complexes of 4,10,15-tritolylcorrole in which $-\mathrm{NO}_{2}$ and - $\mathrm{Br}$ groups are present in different amounts and peripheral positions. In order to better elucidate the photophysical properties of these systems, we have undertaken a careful theoretical study on some nitrated and halogenated phosphorus tritolylcorrole complexes by using the density functional level of theory. Particular emphasis has been devoted to those photophysical parameters that are crucial for the utilization of these systems as photosensitizers 
in photodynamic therapy. Moreover, since an efficient intersystem crossing is an essential requirement for a photodynamic therapy (PDT) candidate, to improve those physical properties we also introduced a structural modification in two of the investigated compounds by replacing the bromine with an iodine substituent and analyzing the resultant effect.

PDT is a mini-invasive procedure used in different medical applications ranging from tumor therapy, atherosclerosis, and inactivation of some bacteria and viruses and insecticides [19-22]. The key cytotoxic agent in PDT is the singlet molecular oxygen $\left({ }^{1} \Delta_{\mathrm{g}}\right)$ generated in situ by energy transfer from an excited sensitizer to the ground electronic state of oxygen molecules $\left({ }^{3} \Sigma_{\mathrm{g}}\right)$. Consequently, despite its success [23-27], one of the main drawbacks of PDT is associated with the lack of oxygen usually observed in several tumors. Indeed, in hypoxic conditions, where oxygen concentrations are already low due to slow diffusion of the gas molecule in the tumor tissue, PDT may fail, leading to resistances [24,27], and other approaches should be used [28]. On the contrary, in oxygenated environments, the therapy can be applied and usually starts with the administration of a photosensitizing agent (PS) which is excited from its electronic ground state $\left(\mathrm{S}_{0}\right)$ to a singlet excited state $\left(S_{n}\right)$ by using light of a specific wavelength and intensity. The excited triplet state generated through a radiation-less intersystem crossing transition, under certain conditions can transfer its energy to the ground state molecular oxygen $\left({ }^{3} \Sigma_{\mathrm{g}}\right)$ generating cytotoxic singlet oxygen $\left({ }^{1} \Delta_{\mathrm{g}}\right)$ (type II photoreactions). The excited PS can also react directly with the organic substrates present in the irradiated tissue by electron exchange, producing radical intermediates that are subsequently scavenged by oxygen, with the formation of the superoxide oxygen radical species and other highly reactive radicals (type I photoreactions).

In order to obtain a type II reaction working mechanism, an efficient PDT photosensitizer should possess the following main photophysical properties:

(a) a low fluorescence quantum yield, which ensures a higher probability that the excited state $S_{1}$ could decay into the triplet excited one;

(b) a triplet state with sufficient energy to generate the excited ${ }^{1} \Delta_{g}$ molecular oxygen. Since the energy necessary to obtain excited molecular oxygen is known to be $0.98 \mathrm{eV}$, [29] the PS triplet excited state must lie above this limit;

(c) an efficient intersystem crossing between singlet and triplet states. To do this, a high spin-orbit coupling constant is necessary as it can be deduced from the expression of the ISC kinetic constant derived from the Fermi Golden Rule [30].

Furthermore, in order to maximize the tissue penetration, an appropriate absorption wavelength falling within the so-called therapeutic window $(550-850 \mathrm{~nm})$ is required.

Of course, other particular properties such as solubility in aqueous media, redox stability, absence of intermolecular aggregation phenomena which decreases the photodynamic action, and no toxicity in the dark, are necessary to propose new molecules as PDT photosensitizers [31].

\section{Computation Details}

All the calculations were performed at the density functional theory level (DFT) and its time-dependent density functional linear response formulation (TDDFT) as implemented in the Gaussian09 code [32]. No symmetry constraints were imposed during the geometry optimizations. On the basis of our previous experience of the photophysical properties of similar systems [33-36], ground and excited state optimization were performed by using the B3LYP [37,38] exchange and correlation functional coupled with the $6-31 \mathrm{G}^{*}$ basis sets for all the atoms excepts for iodine for which the SDD pseudopotential [39] was employed.

The lowest twenty vertical excitation energies were calculated on the previously optimized geometries by adding a diffuse function to the basis set $\left(6-31+\mathrm{G}^{*}\right)$. Solvent effects were included by using the non-equilibrium implementation [40] of the polarizable continuum model [41], taking into account the dielectric media of dichloromethane $(\varepsilon=8.93)$ since the experimental data are available for that solvent. 
Spin-orbit matrix elements $\left\langle S_{1}\left|H_{S O}\right| T_{j}\right\rangle$ were computed by using the quadratic-response TDDFT approach [42,43], as implemented in the Dalton code [44]. For compounds $\mathbf{4}$ and $\mathbf{5}$ where iodine atoms are present, the spin-orbit coupling operators for effective core potentials with an effective nuclear charge [45] was employed, as also previously done with systems containing heavy atoms [46-48]. The atomic-mean field approximation [49] was used instead for the other cases. For this purpose, B3LYP functional in conjunction with cc-pVDZ basis set was employed for all the atoms except iodine, for which the coupled pseudopotential was considered.

\section{Results and Discussion}

The structures of the five examined systems are depicted in Scheme 1.

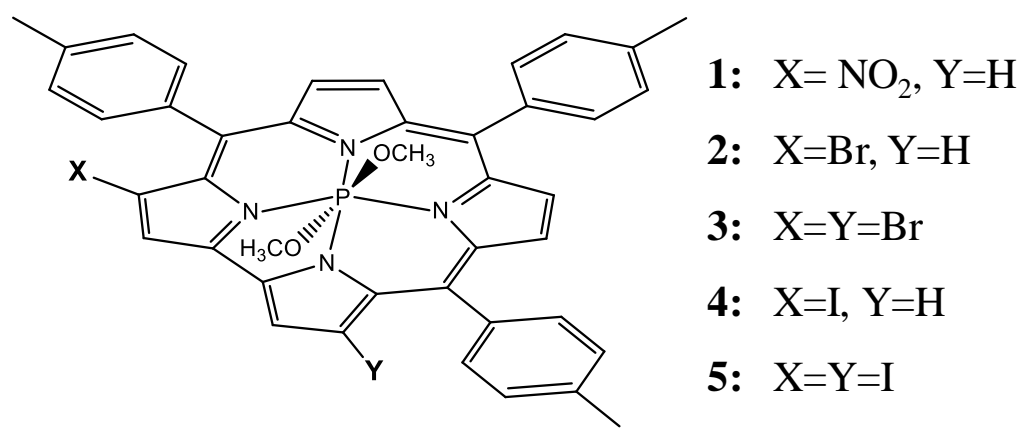

Scheme 1. Schematic representation of compounds investigated in this work.

The phosphorus atom is always coordinated by two $-\mathrm{OCH}_{3}$ group in the axial position and through the four nitrogen atoms of the corrole ring. The presence of different peripheral substituents ( $X$ and $Y$ in Scheme 1) in compounds 1-5 allow us to shed light on the effect of a mono- or bi-heavy atom substitutions on these kinds of systems.

The computed vertical excitation energies for singlet and triplet states, their oscillator strengths, the nature of the orbitals involved in each transition together with the available experimental information, are collected in Table 1.

Comparison with the experimental data, which is only possible for compounds 1-3 in dichloromethane [13], reveals an overall satisfactory agreement between the experimental and computed spectra. The average error registered is $24 \mathrm{~nm}$ and the maximum deviation $(44 \mathrm{~nm})$ occurs for the $S_{1}$ absorption of compound 1.

The substitution of the $\mathrm{NO}_{2}$ group with a halogen atom causes a significant blue shift of the maximum absorption $S_{1}$ band for all the investigated compounds $2-5$, When a bromine or an iodine replace the nitro group in structures 2 and 4 , the $S_{1}$ band experiences a shift of $114 \mathrm{~nm}$ toward smaller wavelengths, and the computed spectra of the mono-halogen substituted corroles $\mathbf{2}$ and $\mathbf{4}$ are essentially the same. The introduction of the second halogen atom in $Y$ position, generating structures 3 and $\mathbf{5}$, does not introduce any significant effect on the UV-VIS spectra compared to $\mathbf{2}$ and $\mathbf{4}$, as can be deduced from Table 1. Actually, the nitro group significantly stabilizes the LUMO (L) orbital with a consequent reduction in the H-L gap compared with those observed for the halogen-derivatives. Indeed, looking at the Gouterman frontier orbital energies (Figure 1), the H-L energy gap goes from the value of $2.27 \mathrm{eV}$ in 1 to about $2.56 \mathrm{eV}$ in the other compounds.

Two triplet states, $T_{1}$ and $T_{2}$, and another three $\left(T_{1}, T_{2}\right.$ and $\left.T_{3}\right)$ lie below the first $S_{1}$ state, for 1 and for $\mathbf{2}-\mathbf{5}$ compounds, respectively, as can be observed in Table 1. All the triplet states possess sufficient energy to promote the formation of the cytotoxic excited singlet oxygen species ${ }^{1} \Delta_{\mathrm{g}}$, that is, their energy is higher than the $0.98 \mathrm{eV}$ required for the $\mathrm{O}_{2}$ triplet to singlet transition. The $\mathrm{T}_{1}$ states are all originated by $\mathrm{H} \rightarrow \mathrm{L}$ transitions while $\mathrm{T}_{2}$ is mainly $(92 \%) \mathrm{H}-1 \rightarrow \mathrm{L}$ in nature in complex 1 . The situation is different for the halogenated systems in which $\mathrm{T}_{2}$ and $\mathrm{T}_{3}$ are always originated from $\mathrm{H} \rightarrow \mathrm{L}+1$ and $\mathrm{H}-1 \rightarrow \mathrm{L}$ transitions with almost the same contribution (about $50 \%$ ), as reported in 
Table 1 . The presence of peripheral halogen substitution increases the $T_{1}$ energy value as a result of a destabilization of the LUMO orbital that is observed when the nitro group is replaced by a halogen substituent. Indeed, the $\mathrm{T}_{1}$ energy passes from $1.18 \mathrm{eV}$ in the case of molecule $\mathbf{1}$ to about $1.40 \mathrm{eV}$ in the 2-5 complexes.

As discussed in the introduction, besides the need for the correct energy value of the triplet states, a photosensitizer should possess a low fluorescence quantum yield and an efficient nonradiative intersystem crossing between singlet and triplet electronic states to produce the singlet oxygen molecule.

Table 1. B3LYP/6-31 + G * vertical excitation energies, $\Delta \mathrm{E}(\mathrm{eV}), \lambda(\mathrm{nm})$, oscillator strengths $f$ and main transitions $(\mathrm{H}=\mathrm{HOMO}, \mathrm{L}=\mathrm{LUMO})$ for studied compounds, computed in dichloromethane. Experimental values are taken from [13].

\begin{tabular}{|c|c|c|c|c|c|c|}
\hline Cmpd. & State & $\Delta \mathrm{E}$ & $\lambda$ & $f$ & Transitions & $\lambda_{\exp }$ \\
\hline \multirow[t]{6}{*}{1} & $\mathrm{~S}_{1}$ & 1.84 & 673 & 0.275 & $\mathrm{H} \rightarrow \mathrm{L}(93 \%)$ & 635 \\
\hline & $\mathrm{S}_{2}$ & 2.19 & 566 & 0.161 & $\mathrm{H}-1 \rightarrow \mathrm{L}(75 \%)$ & 590 \\
\hline & $\mathrm{S}_{3}$ & 2.68 & 463 & 0.439 & $\mathrm{H} \rightarrow \mathrm{L}+1(64 \%)$ & 447 \\
\hline & $\mathrm{S}_{4}$ & 3.18 & 390 & 0.559 & $\mathrm{H}-1 \rightarrow \mathrm{L}+1(29 \%), \mathrm{H}-4 \rightarrow \mathrm{L}(29 \%)$ & 428 \\
\hline & $\mathrm{T}_{1}$ & 1.18 & 1050 & & $\mathrm{H} \rightarrow \mathrm{L}(96 \%)$ & \\
\hline & $\mathrm{T}_{2}$ & 1.62 & 766 & & $\mathrm{H}-1 \rightarrow \mathrm{L}(92 \%)$ & \\
\hline \multirow[t]{7}{*}{2} & $\mathrm{~S}_{1}$ & 2.22 & 559 & 0.310 & $\mathrm{H} \rightarrow \mathrm{L}(86 \%)$ & 599 \\
\hline & $\mathrm{S}_{2}$ & 2.37 & 522 & 0.007 & $\mathrm{H}-1 \rightarrow \mathrm{L}(54 \%), \mathrm{H} \rightarrow \mathrm{L}+1(45 \%)$ & 526 \\
\hline & $\mathrm{S}_{3}$ & 3.03 & 405 & 1.112 & $\mathrm{H} \rightarrow \mathrm{L}+1(52 \%), \mathrm{H}-1 \rightarrow \mathrm{L}(44 \%)$ & 421 \\
\hline & $\mathrm{S}_{4}$ & 3.18 & 390 & 1.066 & $\mathrm{H}-1 \rightarrow \mathrm{L}+1(82 \%)$ & 410 \\
\hline & $\mathrm{T}_{1}$ & 1.41 & 879 & & $\mathrm{H} \rightarrow \mathrm{L}(99 \%)$ & \\
\hline & $\mathrm{T}_{2}$ & 1.76 & 705 & & $\mathrm{H} \rightarrow \mathrm{L}+1(55 \%), \mathrm{H}-1 \rightarrow \mathrm{L}(43 \%)$ & \\
\hline & $\mathrm{T}_{3}$ & 1.96 & 632 & & $\mathrm{H}-1 \rightarrow \mathrm{L}(56 \%), \mathrm{H} \rightarrow \mathrm{L}+1(43 \%)$ & \\
\hline \multirow[t]{7}{*}{3} & $\mathrm{~S}_{1}$ & 2.24 & 555 & 0.295 & $\mathrm{H} \rightarrow \mathrm{L}(86 \%)$ & 599 \\
\hline & $\mathrm{S}_{2}$ & 2.39 & 520 & 0.011 & $\mathrm{H}-1 \rightarrow \mathrm{L}(56 \%), \mathrm{H} \rightarrow \mathrm{L}+1(43 \%)$ & 527 \\
\hline & $\mathrm{S}_{3}$ & 3.07 & 404 & 1.176 & $\mathrm{H} \rightarrow \mathrm{L}+1(54 \%), \mathrm{H}-1 \rightarrow \mathrm{L}(41 \%)$ & 422 \\
\hline & $\mathrm{S}_{4}$ & 3.21 & 386 & 0.995 & $\mathrm{H}-1 \rightarrow \mathrm{L}+1(83 \%)$ & 411 \\
\hline & $\mathrm{T}_{1}$ & 1.40 & 885 & & $\mathrm{H} \rightarrow \mathrm{L}(99 \%)$ & \\
\hline & $\mathrm{T}_{2}$ & 1.78 & 697 & & $\mathrm{H} \rightarrow \mathrm{L}+1(50 \%), \mathrm{H}-1 \rightarrow \mathrm{L}(48 \%)$ & \\
\hline & $\mathrm{T}_{3}$ & 1.97 & 629 & & $\mathrm{H}-1 \rightarrow \mathrm{L}(51 \%), \mathrm{H} \rightarrow \mathrm{L}+1(48 \%)$ & \\
\hline \multirow[t]{7}{*}{4} & $\mathrm{~S}_{1}$ & 2.22 & 559 & 0.318 & $\mathrm{H} \rightarrow \mathrm{L},(86 \%)$ & \\
\hline & $\mathrm{S}_{2}$ & 2.37 & 522 & 0.008 & $\mathrm{H}-1 \rightarrow \mathrm{L}(54 \%), \mathrm{H} \rightarrow \mathrm{L}+1(45 \%)$ & \\
\hline & $\mathrm{S}_{3}$ & 3.04 & 407 & 1.101 & $\mathrm{H} \rightarrow \mathrm{L}+1(51 \%), \mathrm{H}-1 \rightarrow \mathrm{L}(42 \%)$ & \\
\hline & $\mathrm{S}_{4}$ & 3.18 & 390 & 1.069 & $\mathrm{H}-1 \rightarrow \mathrm{L}+1(82 \%)$ & \\
\hline & $\mathrm{T}_{1}$ & 1.41 & 877 & & $\mathrm{H} \rightarrow \mathrm{L}(99 \%)$ & \\
\hline & $\mathrm{T}_{2}$ & 1.76 & 706 & & $\mathrm{H} \rightarrow \mathrm{L}+1(54 \%), \mathrm{H}-1 \rightarrow \mathrm{L}(44 \%)$ & \\
\hline & $\mathrm{T}_{3}$ & 1.96 & 632 & & $\mathrm{H}-1 \rightarrow \mathrm{L}(56 \%), \mathrm{H} \rightarrow \mathrm{L}+1(43 \%)$ & \\
\hline \multirow[t]{7}{*}{5} & $\mathrm{~S}_{1}$ & 2.23 & 556 & 0.311 & $\mathrm{H} \rightarrow \mathrm{L}(86 \%)$ & \\
\hline & $\mathrm{S}_{2}$ & 2.39 & 519 & 0.014 & $\mathrm{H}-1 \rightarrow \mathrm{L}(57 \%), \mathrm{H} \rightarrow \mathrm{L}+1(42 \%)$ & \\
\hline & $\mathrm{S}_{3}$ & 3.05 & 406 & 1.186 & $\mathrm{H} \rightarrow \mathrm{L}+1(53 \%), \mathrm{H}-1 \rightarrow \mathrm{L}(40 \%)$ & \\
\hline & $\mathrm{S}_{4}$ & 3.22 & 385 & 1.018 & $\mathrm{H}-1 \rightarrow \mathrm{L}+1(82 \%)$ & \\
\hline & $\mathrm{T}_{1}$ & 1.40 & 887 & & $\mathrm{H} \rightarrow \mathrm{L}(99 \%)$ & \\
\hline & $\mathrm{T}_{2}$ & 1.78 & 698 & & $\mathrm{H}-1 \rightarrow \mathrm{L}(50 \%), \mathrm{H} \rightarrow \mathrm{L}+1(48 \%)$ & \\
\hline & $\mathrm{T}_{3}$ & 1.97 & 629 & & $\mathrm{H} \rightarrow \mathrm{L}+1(50 \%), \mathrm{H}-1 \rightarrow \mathrm{L}(49 \%)$ & \\
\hline
\end{tabular}

Generally, the presence of halogen or other heavy atoms decreases the fluorescence decay and increases the ISC rate constant in different kinds of molecular systems $[47,48,50,51]$. This effect has been also observed in corroles complexes. In particular, Shi et al. [52], have shown as the presence of one iodine on the aryl ring of triarylcorroles induces a 4 -fold decrease in fluorescence quantum yield and a 60 -fold increase in intersystem crossing rate constants. More recently, similar behaviors have been observed in other iodinated corrole complexes [18]. Since the ISC rate constant depends 
on the magnitude of the spin-orbit coupling, we have calculated the $\left|\left\langle\Psi_{S_{1}}\left|\hat{H}_{s o}\right| \Psi_{T_{n}}\right\rangle\right|$ values for the different $S_{1}-T_{n}$ possible ISC channels. The obtained results are collected in Table 2 together with the $\mathrm{S}_{1}-\mathrm{T}_{\mathrm{n}}$ energy gaps.

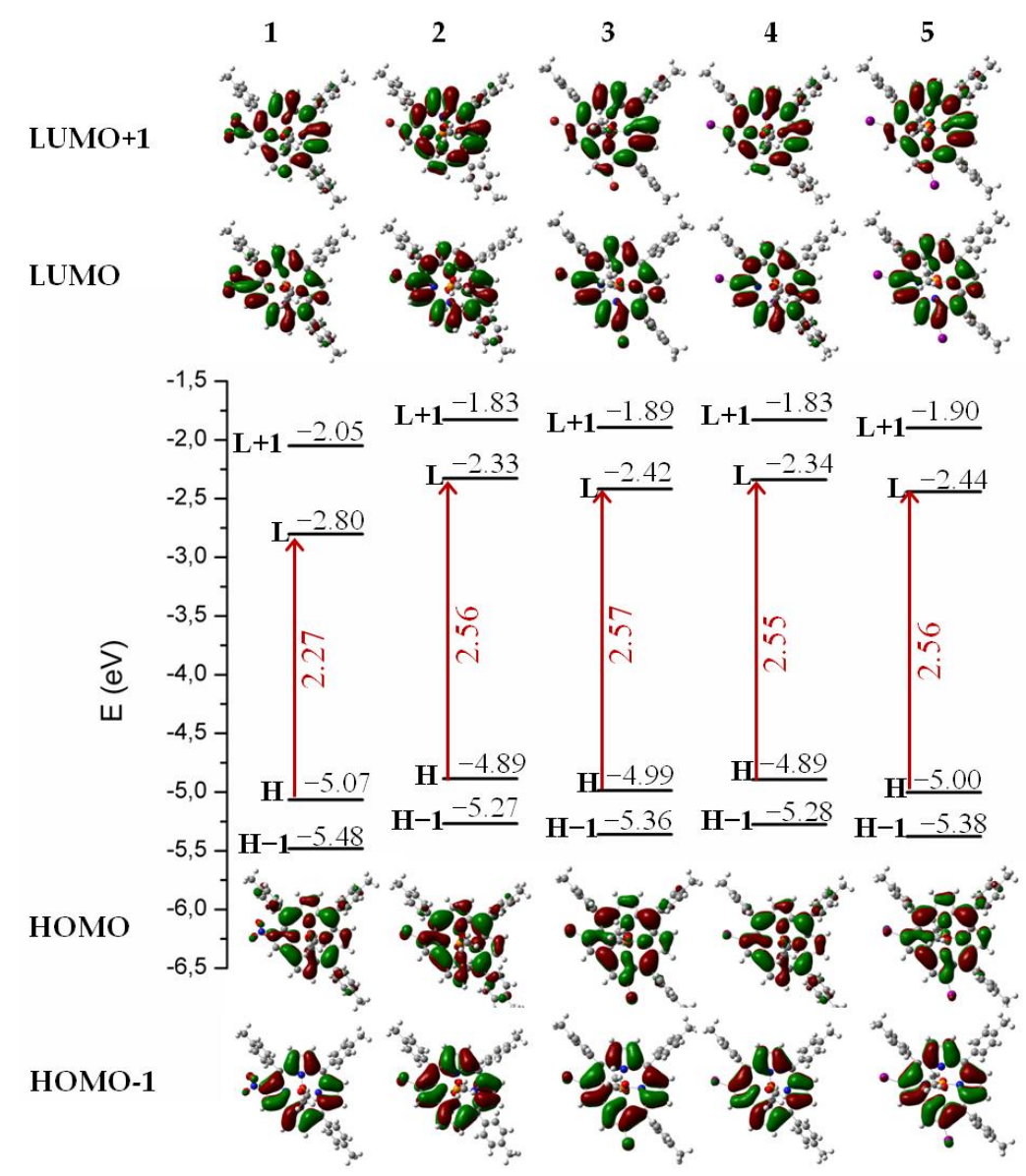

Figure 1. Energy diagram of the four Gouterman's orbital and their counter plot for the ground states of compounds 1-5. H-L energy gaps (eV) are indicated by solid red arrows.

Table 2. Spin-orbit matrix elements $\left(\mathrm{cm}^{-1}\right)$ and singlet-triplet energy gaps $(\mathrm{eV})$ calculated at the B3LYP/cc-pVDZ level of theory.

\begin{tabular}{|c|c|c|c|c|c|c|}
\hline Cmpd. & $\mathrm{I}\left\langle\boldsymbol{\Psi}_{S_{1}}\left|\hat{\boldsymbol{H}}_{s o}\right| \Psi_{T_{1}}\right\rangle \mid$ & $\Delta \mathrm{E}_{\mathrm{S} 1-\mathrm{T} 1}$ & $\mathrm{I}\left\langle\boldsymbol{\Psi}_{S_{1}}\left|\hat{H}_{s o}\right| \Psi_{T_{2}}\right\rangle \mathrm{I}$ & $\Delta \mathrm{E}_{\mathrm{S} 1-\mathrm{T} 2}$ & $\mathrm{I}\left\langle\Psi_{S_{1}}\left|\hat{H}_{s o}\right| \Psi_{T_{3}}\right\rangle \mid$ & $\Delta \mathrm{E}_{\mathrm{S} 1-\mathrm{T} 3}$ \\
\hline 1 & 0.48 & 0.66 & 0.35 & 0.22 & & \\
\hline 2 & 0.28 & 0.81 & 0.67 & 0.46 & 0.32 & 0.26 \\
\hline 3 & 0.26 & 0.84 & 0.76 & 0.46 & 0.27 & 0.27 \\
\hline 4 & 13.10 & 0.81 & 35.0 & 0.46 & 5.4 & 0.26 \\
\hline 5 & 8.54 & 0.83 & 77.27 & 0.45 & 12.65 & 0.26 \\
\hline
\end{tabular}

From the values reported in that table, it is evident that the effect of the peripheral bromine substitution in compounds 2 and 3, is negligible for all the considered spin-orbit coupling (SOC) constants.

On the contrary, iodine causes SOCs to increase by one or two order of magnitude compared with brominated ones and the $\mathrm{S}_{1}-\mathrm{T}_{2}$ channel to have the highest value.

The Gouterman molecular orbital plots for the excited singlet and triplet electronic states involved in the considered ISC events for system $\mathbf{2}$ and $\mathbf{4}$ are reported in Figure 2, to provide some insights on the origin of these effects. Actually, the matrix elements of the spin-orbit couplings vary strongly from 
compound 2, containing the bromine atom to 4, in which an iodine is present instead. Thus we chose to compare these two systems.

H-1
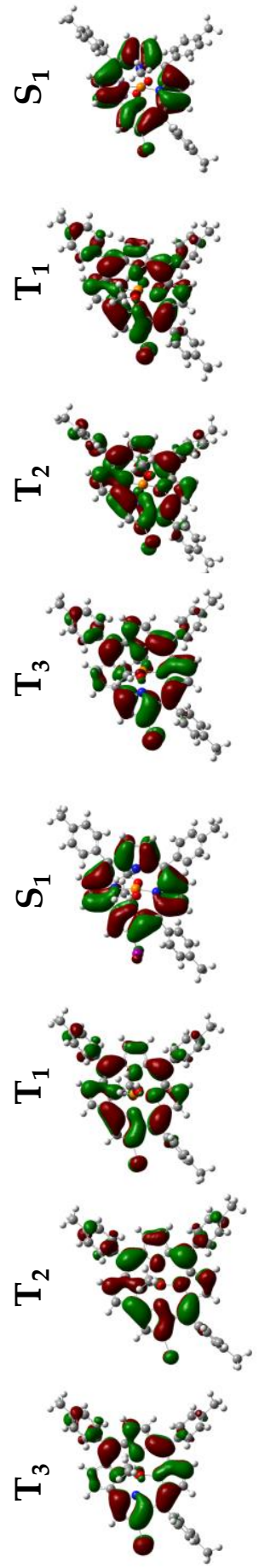

$\mathbf{H}$
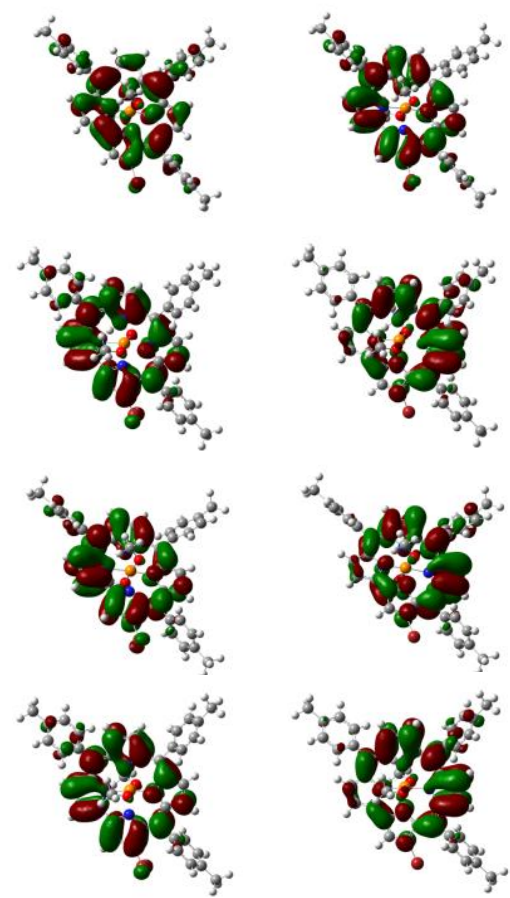

4
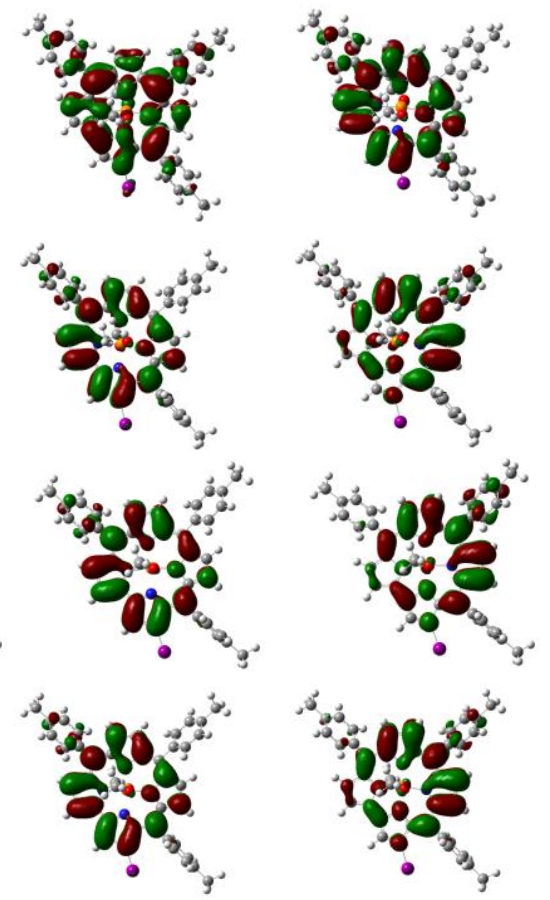

$\mathrm{L}+1$
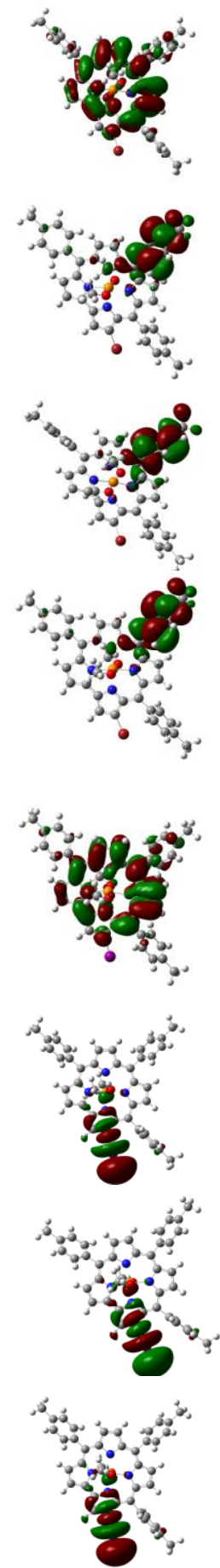

Figure 2. Molecular orbital contour plots for selected excited states of systems 2 and 4.

According to the El Sayed rules [53], high SOC values are obtained if the transition takes place with a change in the composition of the molecular orbitals involved. Therefore, we analysed the most important channels for compounds 2 and 4. 
The molecular orbitals involved in the ISC between $S_{1}$ and $T_{1}$ in compound $\mathbf{2}$ and 4 are HOMO and LUMO (Table 1), and both possess a $\pi$ character (Figure 2). Due to the similar nature of the involved orbitals, the increment of SOC values due to the presence of a heavy atom like iodine in 4 is not so significant for this channel. On the contrary, the computed values for $\mathrm{S}_{1}-\mathrm{T}_{2}$ ISC mechanisms reveal an important role of the iodine substituent. Actually, the $S_{1}-T_{2}$ ISC for compound 2 occurs between a $\pi-\pi^{*}$ state $\left(S_{1}, H \rightarrow L\right)$ to another $\pi-\pi^{*}$ state $\left(T_{2}, H \rightarrow L+1\right)$, as it can be deduced looking at Figure 2. When iodinated compound 4 is considered, the nature of the molecular orbitals involved in the ISC channel change significantly. Indeed, while the $S_{1}$ state is still characterized by a $\mathrm{H} \rightarrow \mathrm{L}$ transition having both a $\pi$ nature as in the case of molecule 2 , the $T_{2}$ state is different since the $L+1$ is now entirely located on the lone pairs of the iodine atom. This change in symmetry, as predicted by the El Sayed rules, causes a significant increase of the SOC value for the $S_{1}-T_{2}$ coupling.

A less important increase in the SOC value was obtained for the $S_{1}-T_{3}$ channel of compound 4 compared to molecule 2. Indeed, different to what was observed in the previous case, the contribution of the $\mathrm{H} \rightarrow \mathrm{L}+1$ transition is no more dominant in $\mathrm{T}_{3}$, being the latter one characterized mainly by a $\mathrm{H}$ $-1 \rightarrow \mathrm{L}, \pi-\pi^{*}$ transition. This is why the increment in the SOC value for compound 4 is not as big as that observed for the $\mathrm{S}_{1}-\mathrm{T}_{2}$ channel.

Looking at the obtained values of the spin-orbit coupling for the considered ISC processes, in principle, more than one deactivation pathways could be hypothesized. Starting from the low-lying populated $S_{1}$ state (see the oscillator strengths in Table 1) and considering the presence of three triplet excited states below it for the halogenated systems, the following paths should be possible upon irradiation:

(a) $\mathrm{S}_{0} \stackrel{\mathrm{A}}{\rightarrow} \mathrm{S}_{1} \stackrel{\text { ISC }}{\rightarrow} \mathrm{T}_{3} \stackrel{\text { IC }}{\rightarrow} \mathrm{T}_{2} \stackrel{\text { IC }}{\rightarrow} \mathrm{T}_{1}$

(b) $\quad \mathrm{S}_{0} \stackrel{\mathrm{A}}{\rightarrow} \mathrm{S}_{1} \stackrel{\text { ISC }}{\rightarrow} \mathrm{T}_{2} \stackrel{\text { IC }}{\rightarrow} \mathrm{T}_{1}$

(c) $\mathrm{S}_{0} \stackrel{\mathrm{A}}{\rightarrow} \mathrm{S}_{1} \stackrel{\text { ISC }}{\rightarrow} \mathrm{T}_{1}$

Following the Fermi Golden Rule [30], the intersystem crossing kinetics are directly related to the spin-orbit matrix elements and the Franck-Condon weighted density of states (FCWD). In the framework of Marcus-Levich-Jortner theory [54], the FCWD is proportional to the difference between the energies of the singlet and the triplet states $\Delta \mathrm{E}$ at their equilibrium geometry. Looking at Table 2, where both the computed SOCs and $\triangle E$ s are reported, path (b) is indicated as the preferred one due to the high value of spin-orbit matrix elements and a feasible $\Delta E$ between $S_{1}$ and $T_{2}$. A more precise prediction can only be made by calculating the kinetic constants. Nevertheless, this kind of parameter implies the calculation of the Franck-Condon weighted density of states which is highly expensive for the considered systems. Work is in progress in this area.

\section{Conclusions}

Density functional theory was employed to investigate a series of nitrated and halogenated phosphorus tritolylcorrole complexes focusing on some crucial photophysical properties required by a photosensitizer to be utilized in photodynamic therapy applications. The following conclusions can be made.

The presence of peripheral halogens in place of the $-\mathrm{NO}_{2}$ group, determines a significant blue-shift of the maximum near infrared absorption band. However, the absorption $Q$ band of all the examined compounds is intense and with a wavelength that falls in the so-called photodynamic window.

For all the investigated compounds, the energy of the low-lying triplet state $\left(\mathrm{T}_{1}\right)$ is sufficiently higher than the energy required to excite the molecular oxygen in its ${ }^{1} \Delta_{\mathrm{g}}$ state.

The spin-matrix elements significantly increase when iodine atoms are present as peripheral substituents. For all the five examined compounds the computed SOCs are higher than the corresponding value for the Foscan ${ }^{\circledR}[55]$ system already used in PDT.

We hope that our data could stimulate further investigations on iodine containing phosphorus tritolylcorrole complexes for their possible use as photosensitizers in photodynamic therapy. 
Author Contributions: M.E.A., B.C.D.S., G.M., N.R. and M.T. made equal contributions to the study and the publication of this work.

Funding: This research received no external funding.

Acknowledgments: The University of Calabria is gratefully acknowledged.

Conflicts of Interest: The authors declare no conflict of interest.

\section{References}

1. Johnson, A.W.; Kay, I.T. Synthesis of corroles and related ring systems. Proc. R. Soc. Lond. A 1965, 288, 334-341. [CrossRef]

2. Thomas, K.E.; Alemayehu, A.B.; Conradie, J.; Beavers, C.M.; Ghosh, A. The structural chemistry of metallocorroles: Combined X-ray crystallography and quantum chemistry studies afford unique insights. Acc. Chem. Res. 2012, 45, 1203-1214. [CrossRef] [PubMed]

3. Aviv-Harel, I.; Gross, Z. Coordination chemistry of corroles with focus on main group elements. Coord. Chem. Rev. 2011, 255, 717-736. [CrossRef]

4. Walker, D.C.; Chappel, S.; Mahammed, A.; Brunschwig, B.S.; Winkler, J.R.; Gray, H.B.; Zaban, A.; Gross, Z. The $\pi$-system of corroles is much more electron-rich than of porphyrins, and one consequence is that full bromination (17) and chlorination. J. Porphyr. Phthalocyanines 2006, 10, 1259-1262. [CrossRef]

5. Flamigni, L.; Gryko, D.T. Photoactive corrole-based arrays. Chem. Soc. Rev. 2009, 38, 1635-1646. [CrossRef] [PubMed]

6. Agadjanian, H.; Ma, J.; Rentsendorj, A.; Valluripalli, V.; Hwang, J.Y.; Maham-med, A.; Farkas, D.L.; Gray, H.B.; Gross, Z.; Medina-Kauwe, L.K. Tumor detection and elimination by a targeted gallium corrole. Proc. Natl. Acad. Sci. USA 2009, 106, 610-6105. [CrossRef] [PubMed]

7. Mahammed, A.; Gross, Z. The importance of developing metal complexes with pronounced catalase-like activity. Catal. Sci. Technol. 2011, 1, 535-540. [CrossRef]

8. Mahammed, A.; Gross, Z. Metallocorroles as photocatalysts for driving endergonic reactions, exemplified by bromide to bromine conversion. Angew. Chem. Int. Ed. 2015, 54, 12370-12373. [CrossRef] [PubMed]

9. Hwang, J.Y.; Lubow, J.; Chu, D.; Ma, J.; Agdjanian, H.; Sims, J.; Gray, H.B.; Gross, Z.; Farkas, D.L.; Medina-Kauwe, L.K. A mechanistic study of tumor-targeted corrole toxicity. Mol. Pharm. 2011, 8, 2233-2243. [CrossRef] [PubMed]

10. Simkhovich, L.; Mahammed, A.; Goldberg, I.; Gross, Z. Synthesis and characterization of germanium, tin, phosphorus, iron, and rhodium complexes of tris(pentafluorophenyl)corrole, and the utilization of the iron and rhodium corroles as cyclopropanation catalysts. Chem. Eur. J. 2001, 7, 1041-1055. [CrossRef]

11. Buckley, H.L.; Arnold, J. Recent developments in out-of-plane metallocorrole chemistry across the periodic table. Dalton Trans. 2015, 44, 30-36. [CrossRef] [PubMed]

12. Kobayashi, N.; Furuyama, T.; Satoh, K. Rationally designed phthalocyanines having their main absorption band beyond $1000 \mathrm{~nm}$. J. Am. Chem. Soc. 2011, 133, 19642-19645. [CrossRef] [PubMed]

13. Pomarico, G.; Tortora, L.; Fronczek, F.R.; Smith, K.M.; Paolesse, R. Selective nitration and bromination of surprisingly ruffled phosphorus corroles. J. Inorg. Biochem. 2016, 158, 17-23. [CrossRef] [PubMed]

14. Liang, X.; Mack, J.; Zheng, L.-M.; Shen, Z.; Kobayashi, N. Phosphorus(V)-corrole: Synthesis, spectroscopic properties, theoretical calculations, and potential utility for in vivo applications in living cells. Inorg. Chem. 2014, 53, 2797-2802. [CrossRef] [PubMed]

15. Ghosh, A.; Lee, W.-Z.; Ravikanth, M. Synthesis, structure and properties of a five-coordinate oxophosphorus(V) meso-triphenylcorrole. Eur. J. Inorg. Chem. 2012, 2012, 4231-4239. [CrossRef]

16. Paolesse, R.; Boschi, T.; Licoccia, S.; Khoury, R.G.; Smith, K.M. Phosphorus complex of corrole. Chem. Commun. 1998, 1119-1120. [CrossRef]

17. Kadish, K.M.; Ou, Z.; Adamian, V.A.; Guilard, R.; Gros, C.P.; Erben, C.; Will, S.; Vogel, E. Corroles with group 15 ions. 2. synthesis and characterization of octaethylcorroles containing a phosphorus central atom. Inorg. Chem. 2000, 39, 5675-5682. [CrossRef] [PubMed]

18. Vestfrid, J.; Goldberg, I.; Gross, Z. Tuning the photophysical and redox properties of metallocorroles by iodination. Inorg. Chem. 2014, 53, 10536-10542. [CrossRef] [PubMed] 
19. Kim, H.; Kim, W.; Mackeyev, Y.; Lee, G.-S.; Kim, H.-J.; Tachikawa, T.; Hong, S.; Lee, S.; Kim, J.; Wilson, L.J.; et al. Selective oxidative degradation of organic pollutants by singlet oxygen-mediated photosensitization: Tin porphyrin versus C60 aminofullerene systems. Environ. Sci. Technol. 2012, 46, 9606-9613. [CrossRef] [PubMed]

20. Han, S.K.; Sik, R.H.; Motten, A.G.; Chignell, C.F.; Bilski, P.J. Photosensitized oxidation of tetrabromobisphenol a by humic acid in aqueous solution. Photochem. Photobiol. 2009, 85, 1299-1305. [CrossRef] [PubMed]

21. Kohn, T.; Nelson, K.L. Sunlight-mediated inactivation of MS2 coliphage via exogenous singlet oxygen produced by sensitizers in natural waters. Environ. Sci. Technol. 2007, 41, 192-197. [CrossRef] [PubMed]

22. Romero, O.C.; Straub, A.P.; Kohn, T.; Nguyen, T.H. Role of temperature and suwannee river natural organic matter on inactivation kinetics of rotavirus and bacteriophage MS2 by solar irradiation. Environ. Sci. Technol. 2011, 45, 10385-10393. [CrossRef] [PubMed]

23. DeRosa, M.C.; Crutchley, R.J. Photosensitized singlet oxygen and its applications. Coord. Chem. Rev. 2002, 233-234, 351-371. [CrossRef]

24. Yano, S.; Hirohara, S.; Obata, M.; Hagiya, Y.; Ogura, S.; Ikeda, I.; Kataoka, H.; Tanaka, M.; Joh, T. Current states and future views in photodynamic therapy. J. Photochem. Photobiol. C 2011, 12, 46-67. [CrossRef]

25. Allison, R.R.; Bagnato, V.S.; Sibata, C.H. Future of oncologic photodynamic therapy. Future Oncol. 2010, 6, 929-940. [CrossRef] [PubMed]

26. MacDonald, I.J.; Dougherty, T.J. Basic principles of photodynamic therapy. J. Porphyr. Phthalocyan. 2001, 5, 105-129. [CrossRef]

27. Dolmans, D.E.; Fukumura, D.; Jain, R.K. Photodynamic therapy for cancer. Nat. Rev. Cancer 2003, 3, 380-387. [CrossRef] [PubMed]

28. Gattuso, H.; Dumont, E.; Marazzi, M.; Monari, A. Two-photon-absorption DNA sensitization via solvated electron production: Unraveling photochemical pathways by molecular modeling and simulation. Phys. Chem. Chem. Phys. 2016, 18, 18598-18606. [CrossRef] [PubMed]

29. Herzberg, G. Spectra of Diatomic Molecules, 2nd ed.; Van Nostrand Reinhold: New York, NY, USA, 1950; pp. 344-346.

30. Marian, C.M. Spin-orbit coupling and intersystem crossing in molecules. Wiley Interdiscip. Rev. Comput. Mol. Sci. 2012, 2, 187-203. [CrossRef]

31. Dougherty, T.J.; Gomer, C.J.; Henderson, B.W.; Jori, G.; Kessel, D.; Korbelik, M.; Moan, J.; Peng, Q. Photoradiation therapy. J. Natl. Cancer Inst. 1998, 90, 889-905. [CrossRef] [PubMed]

32. Frisch, M.J.; Trucks, G.W.; Schlegel, H.B.; Scuseria, G.E.; Robb, M.A.; Cheeseman, J.R.; Scalmani, G.; Barone, V.; Mennucci, B.; Petersson, G.A.; et al. Gaussian 09, Revision, D.01; Gaussian, Inc.: Wallingford, CT, USA, 2009.

33. Mazzone, G.; Alberto, M.E.; De Simone, B.C.; Marino, T.; Russo, N. Can expanded bacteriochlorins act as photosensitizers in photodynamic therapy? Good news from density functional theory computations. Molecules 2016, 21, 288. [CrossRef] [PubMed]

34. De Simone, B.C.; Mazzone, G.; Russo, N.; Sicilia, E.; Toscano, M. Excitation energies, singlet-triplet energy gaps, spin-orbit matrix elements and heavy atom effects in BOIMPYs as possible photosensitizers for photodynamic therapy: A computational investigation. Phys. Chem. Chem. Phys. 2018, 20, 2656-2661. [CrossRef] [PubMed]

35. Noimark, S.; Salvadori, E.; Gómez-Bombarelli, R.; MacRobert, A.J.; Parkina, I.P.; Kay, C.W.M. Comparative study of singlet oxygen production by photosensitiser dyes encapsulated in silicone: Towards rational design of anti-microbial surfaces. Phys. Chem. Chem. Phys. 2016, 18, 2810. [CrossRef] [PubMed]

36. Quartarolo, A.D.; Sicilia, E.; Russo, N. On the potential use of squaraine derivatives as photosensitizers in photodynamic therapy: A TDDFT and RICC2 survey. J. Chem. Theory Comput. 2009, 5, 1849-1857. [CrossRef] [PubMed]

37. Becke, A.D. Density-functional thermochemistry. III. The role of exact exchange. J. Chem. Phys. 1993, 98, 5648-5652. [CrossRef]

38. Lee, C.; Yang, W.; Parr, R.G. Development of the colle-salvetti correlation-energy formula into a functional of the electron density. Phys. Rev. B Condens. Matter Mater. Phys. 1988, 37, 785-789. [CrossRef]

39. Andrae, D.; Haussermann, U.; Dolg, M.; Stoll, H.; Preuss, H. Energy-adjusted ab initio pseudopotentials for the second and third row transition elements. Theor. Chim. Acta 1990, 77, 123-141. [CrossRef]

40. Cossi, M.; Barone, V. Solvent effect on vertical electronic transitions by the polarizable continuum model. J. Chem. Phys. 2000, 112, 2427-2435. [CrossRef] 
41. Tomasi, J.; Menucci, B.; Cammi, R. Quantum mechanical continuum solvation models. Chem. Rev. 2005, 105, 2999-3094. [CrossRef] [PubMed]

42. Rinkevicius, Z.; Tunell, I.; Sałek, P.; Vahtras, O.; Ågren, H. Restricted density functional theory of linear time-dependent properties in open-shell molecules. J. Chem. Phys. 2003, 119, 34-46. [CrossRef]

43. Ågren, H.; Vahtras, O.; Minaev, B. Response theory and calculations of spin-orbit coupling phenomena in molecules. Adv. Quantum Chem. 1996, 27, 71-162.

44. Dalton. A Molecular Electronic Structure Program. Release Dalton 2011. Available online: http://daltonpr ogram.org/ (accessed on 24 February 2016).

45. Koseki, S.; Schmidt, M.W.; Gordon, M.S. Effective nuclear charges for the first- through third-row transition metal elements in spin-orbit calculations. J. Phys. Chem. A 1998, 102, 10430-10436. [CrossRef]

46. Alberto, M.E.; Pirillo, J.; Russo, N.; Adamo, C. A theoretical exploration of TypeI/TypeII dual photoreactivity of new promising $\mathrm{Ru}(\mathrm{II})$-dyads for PDT approach. Inorg. Chem. 2016, 55, 11185-11192. [CrossRef] [PubMed]

47. De Simone, B.C.; Mazzone, G.; Russo, N.; Sicilia, E.; Toscano, M. Computational investigation of the influence of halogen atoms on the photophysical properties of tetraphenylporphyrin and its Zinc(II) complexes. J. Phys. Chem. A 2018, 122, 2809-2815. [CrossRef] [PubMed]

48. De Simone, B.C.; Mazzone, G.; Pirillo, J.; Russo, N.; Sicilia, E. Halogen atom effect on the photophysical properties of substituted aza-BODIPY derivatives. Phys. Chem. Chem. Phys. 2017, 19, 2530-2536. [CrossRef] [PubMed]

49. Ruud, K.; Schimmelpfennig, B.; Ågren, H. Internal and external heavy-atom effects on phosphorescence radiative lifetimes calculated using a mean-field spin-orbit Hamiltonian. Chem. Phys. Lett. 1999, 310, $215-221$. [CrossRef]

50. Alberto, M.E.; De Simone, B.C.; Mazzone, G.; Sicilia, E.; Russo, N. The heavy atom effect on Zn(II) phthalocyanine derivatives: A theoretical exploration of the photophysical properties. Phys. Chem. Chem. Phys. 2015, 17, 23595-23601. [CrossRef] [PubMed]

51. Alberto, M.E.; Iuga, C.; Quartarolo, A.D.; Russo, N. Bisanthracene bis(dicarboxylic imide)s as potential photosensitizers in photodynamic therapy. A theoretical investigation. J. Chem. Inf. Model. 2013, 53, 2334-2340. [CrossRef] [PubMed]

52. Shi, L.; Liu, H.Y.; Shen, H.; Hu, J.; Zhang, G.L.; Wang, H.; Ji, L.N.; Chang, C.K.; Jiang, H.F. Fluorescence properties of halogenated mono-hydroxyl corroles: The heavy-atom effects. J. Porphyr. Phthalocyanines 2009, 13, 1221-1226. [CrossRef]

53. El-Sayed, M.A. Triplet state. Its radiative and nonradiative properties. Acc. Chem. Res. 1968, 1, 8-16. [CrossRef]

54. Peterson, K.A.; Shepler, B.C.; Figgen, D.; Stoll, H. On the spectroscopic and thermochemical properties of $\mathrm{ClO}, \mathrm{BrO}, \mathrm{IO}$, and their anions. J. Phys. Chem. A 2006, 110, 13877-13883. [CrossRef] [PubMed]

55. Alberto, M.E.; Marino, T.; Quartarolo, A.D.; Russo, N. Photophysical origin of the reduced photodynamic therapy activity of temocene compared to Foscan ${ }^{\circledR}$ : Insights from theory. Phys. Chem. Chem. Phys. 2013, 15, 16167-16171. [CrossRef] [PubMed]

(C) 2018 by the authors. Licensee MDPI, Basel, Switzerland. This article is an open access article distributed under the terms and conditions of the Creative Commons Attribution (CC BY) license (http://creativecommons.org/licenses/by/4.0/). 